\title{
Criminology or Zemiology? Yes, Please! On the Refusal of Choice between False Alternatives. \\ Justin Kotzé
}

\begin{abstract}
:
Buried deep within the zemiological movement and its supportive literature is the implicit assumption that the word zemia, the organising concept around which zemiology is built, simply represents 'the Greek word for harm'. This interpretation has supported numerous drives to 'move beyond criminology' and erect strict borders between the study of crime and harm. However a deeper, albeit still rather brief, exploration of zemia reveals that it possesses a broader range of meaning than that commonly afforded to it. By beginning to unpick zemia's semantic genealogy, it appears that the conventional use of the word to support the imposition of false alternatives between criminology and zemiology is untenable. Accordingly, this chapter attempts to foreground a more integrated approach to the study of crime and harm.
\end{abstract}

\section{Biography:}

Justin Kotzé is a Senior Lecturer in Criminology and Criminal Justice at Teesside University. He was awarded his $\mathrm{PhD}$ in 2016 and maintains an interest in analysing the 'crime decline', the mutation of crime, and social harm. Justin has previously published work in the fields of ex-prisoner reintegration and the historical sublimation of violence.

\section{Introduction:}

The discipline of criminology has long been beset by a nagging tension that seemingly runs right to its heart. That is, the tension between the concepts of 'crime' and 'harm'. Debates 
regarding the appropriateness of the terms' conceptual boundaries, range of theoretical efficacy and empirical operationalisation have occupied scholars, particularly those on the margins of criminology's boundaries, for years (Pemberton 2016; Hughes 2006). Indeed, the issues raised by these debates continue to animate scholars who appear determined to settle the issue, to finally put to bed a tension that has in many ways become regarded as innate to the discipline. Certainly one of the most concerted efforts to lay bare the complexities of this long running tension, albeit from a particular view, can be found in the landmark study Beyond Criminology: Taking Harm Seriously (Hillyard et al. 2004a). Authored by a less than unified congregation of scholars (Pemberton 2016; Hillyard 2013) the text draws attention to both conceptual issues and empirical blind spots that pervade and impair the mainstream criminological enterprise. Notwithstanding the broad and diverse range of positions occupied by the contributors, the works that make up this collection take great pains to stress "the perceived deficiencies of the concept of crime as a lens to capture the full range of harms that impact on our lives" (Pemberton 2016, 4).

Although such deficiencies have been well highlighted before the publication of Beyond Criminology (see for example Muncie 2000; Henry and Lanier 1998; Milovanovic and Henry 2001; Henry and Milovanovic 1996; Tifft and Sullivan 2001), students of criminology and zemiology are often encouraged to view the aforementioned text as the decisive voice in challenging criminological constraints. This, however, has salient implications. Whilst scholars such as Muncie (2000), for instance, have advocated the utility of reconceptualising criminology's legitimate domain of inquiry so as to decentre 'crime' as the sole object of study and broaden its focal concerns beyond myopic understandings of the 'crime problem', some of those associated with the latter movement have been less subtle. Rather than aiming to "significantly extend the legitimate parameters of criminological study away from a limited focus on those injurious acts defined as such by the criminal law" 
(Hopkins Burke 2014, 256), the message conveyed by Hillyard et al. (2004b) is to move entirely beyond criminology, as only then, we are told, may we be able to 'take harm seriously'. Essentially, what develops here is a binary between those who wish to extend the legitimate parameters of criminology to incorporate a wider range of un-criminalised and hidden harms as serious focal concerns within its orbit of inquiry, and those who wish to dispense with the discipline entirely. Accordingly, there now exists a palpable tension not only between the concepts of 'crime' and 'harm' but between the disciplines apparently charged with their investigation, criminology and zemiology.

However, we may wish to question the accuracy and efficacy of delimiting strict borders between these subjects. In fact, a closer reading of the term zemia, which forms the conceptual basis of zemiology, reveals much in this regard. Much like the Latin origin of the word 'crime', crimen, which was heavily imbued with broad notions of harm (Muncie, Talbot, and Walters 2010), the Greek term zemia denotes much more than harm. Yet despite connoting harm, loss, and punishment, among other things, the rough translation of zemia as 'the Greek word for harm' permeates the literature (Hillyard et al. 2004b; Hillyard 2013; Pemberton 2016; Loader and Sparks 2011) and reinforces the idea that criminology is for crime and zemiology is for harm. This raises two important questions. Firstly, has the term zemia, as the basis for zemiology, been adequately explored and applied? Secondly, does a more holistic reading of the term substantiate the tendency to position crime and harm, and criminology and zemiology, as diametric opposites? The purpose of this chapter is to explore these questions. By offering both critique and avenues for further development it is hoped that it may in some way contribute to ongoing discussions relating to the fracture between criminology and zemiology. As Hillyard and Tombs $(2017,296)$ rightly point out, such dialogical advancement not only signals genuine engagement with previous work but is "the stuff of healthy academic life". 


\section{Exploring Zemia}

Somewhat surprisingly, the nuanced lexical formation of zemia, the central concept around which zemiology has been organised, has received limited attention. Indeed, even in the pioneering work of Beyond Criminology, reference to the term zemia occurs only once in a fleeting gesture of explanation. The editors, in an attempt to clarify the naming of this new discipline, note that "[t]he new discipline was termed Zemiology from the Greek Zemia, meaning harm" (Hillyard et al. 2004b, 276). Later, Hillyard (2013, 220) reveals the circumstances surrounding this decision making process:

A few of the Bristol Group were chatting in the sun with Professor Vassilis Karydis and I asked him what was the Greek word for harm and he said it was zemia, hence zemiology. The study of harm as a new comprehensive discipline distinct from criminology was therefore born.

This somewhat circumstantial naming process has had profound and lasting effects. Subsequent authors have uncritically adopted this interpretation and continue to advance a seemingly intuitive homology between the term zemia, the concept of harm and the 'zemiological' study of phenomena so conceptualised. For instance, Loader and Sparks $(2011,151)$ note that the term zemiology "derives from the Greek word 'zemia' meaning harm”. Similarly, Pemberton (2016, 6, original emphasis) states that “...zemiology, derived from the Greek xemia for harm, denotes the study of harm". As a final example, an entry in the third edition of The Sage Dictionary of Criminology adds in parenthesis, following the word 'zemiology', “from the Greek zemia, meaning harm” (Muncie 2013, 430, original emphasis). As a text often recommended to undergraduate criminology students as introductory reading, this vague interpretation of zemia is particularly problematic. 
This issue should not be cast aside or rated a second order concern, a matter of 'mere semantics', since greater semantic analysis is precisely what is required here. As alluded to previously, further development of this line of inquiry is salient for in its current dominant translation/interpretation the term zemia remains devoid of its numerous other connotations and is therefore stilted and rather limiting. Restricted to a single meaning, zemia has become both a limited organizing concept of the emerging zemiology and the justification for its sole focus upon 'social harm' and the exclusion of 'criminal harm' (Pemberton 2016). Accordingly, a deeper exploration of zemia is needed. This requires an effort to trace with more accuracy the subtle nuances in the lexical formation of zemia (Boukli 2019). In doing so one is able to register understated interconnections between its various connotations and in turn question the efficacy of the dominant drive to carve out a 'zemiological niche' that focuses only upon a bounded conception of harm, artificially divorced from the broader facets with which the term zemia is concerned.

The word zemia is often understood to mean 'hurt', 'damage' (Saunders 1991) and, among other things, the imposition of 'harm' or 'loss' upon an individual (Cairns 2015). These understandings are perhaps the closest fit to the dominant reading of zemia currently employed throughout much of the social harm literature. Indeed, within this growing body of work copious references are made to various forms of financial, physical, psychological and environmental losses and damage which impinge upon basic human needs, rights and planetary well-being. This includes, but is not limited to, poverty, debt, malnutrition, inadequate housing, the proliferation of preventable illness and disease, pollution, habitat destruction, accelerated animal extinction, resource depletion, genocide and numerous other deleterious events or absences, often associated with either too little or too much state intervention (Hillyard and Tombs 2007; Muncie 2000). As an illustration of this 'closeness of fit', Henry and Milovanovic (1996, 103, emphasis added) refer to harms of reduction as 
constituting “... a loss of some quality relative to [one's] present standing”. Moreover, harms of repression are said to occur when one experiences a restriction or disadvantage, preventing the achievement of a desired outcome or standing (Henry and Milovanovic 1996). Similarly, Tifft and Sullivan $(2001,198)$ define social harms as "actions or arrangements that physically and spiritually injure and/or thwart the needs, development, potentiality, health, and dignity of others"; in other words, the perpetuation of social conditions that facilitate the mass production of what Bauman $(2004,5)$ refers to as "'human waste', or more correctly wasted humans".

While much of the social harm literature acknowledges the intellectual debt owed to early pioneers such as Sutherland (1945) and the Schwendingers (1975), the debt evidently runs much deeper. For example, Aristotle identifies 'the just' (to dikaion) as constituting the mean between gain (kerdos) and loss (zemia) (O’Connor 1991). Any deviation from this mean is to "transgress an external standard of distributive fairness" and therefore constitutes injustice (Balot 2001, 27; Boukli 2019). For Aristotle, injustice may also derive from forms of wastefulness that lead to harm to others (O'Connor 1991). Another reading of zemia provided by Allen $(2000,69)$ indicates that in classical Athenian society "zemia primarily meant 'harmful loss' or 'payment"' and understood outside the context of punishment the word "linked the process of punitive exchange to the process of monetary exchange and to the status of citizens as economic actors".

Interestingly, the word zemia can also be understood in the context of punishment. According to Saunders $(1991,3)$ the Greeks historically "had no single word for 'punishment"' but among the more notable terms we find zemia which Saunders $(1991,4)$ takes to denote “'hurt', 'damage', especially loss of money, suffered by offender by way of retaliation, hence 'penalty"'. Similarly, its cognate term zemioun means "“to damage', 'to fine"” (Saunders 1991, 4). Accordingly the word zemia and its cognate terms describe 
retaliatory procedures that may naturally be viewed as the enactment of punishment (Saunders 1991). Cairns (2015) highlights the use of the word zemia in Athenian homicide speeches to denote the imposition of a lawful penalty upon an individual who has been convicted, in a legal context, of an offence. Additionally, Versnel (1992) recounts how zemia is also used to convey a kind of ritualised punishment/penalty imposed for the committal of an offence in an attempt to expiate wrongdoings. Allen (2000) also identifies a number of punitive words used in fourth century Greece to signify punishment, among which she notes the word zemia as denoting penalty. In this context, zemia and its cognate zemioo (to suffer damage) refer to the effect or consequence punishment has on the wrongdoer rather than a "set of relations between people or their roles in punishment" (Allen 2000, 69). Allen (2000, 174) further demonstrates the punitive tones zemia possesses by referring to Demosthenes' explicit description of laws as a codified delineation of how much anger should be ascribed to various wrongdoings: "Observe that the laws treat the wilful and hubristic wrongdoer as worthy of greater anger (orge) and punishment (zemia)".

From this brief exploration of zemia we can see that it possesses greater lexical diversity than it is commonly credited with (see also Boukli and Kotzé, this volume; Boukli 2019). Certainly, from this view there is a discernible relationship between zemia, jurisprudence and the punishment of legal transgression, commonly referred to as 'crime'. Yet the meaning of this relationship is by no means straightforward, for contained within the above paragraph is a complex dyad. On the one hand we may note the obvious reference in Allen (2000) to the harmful effects and consequences of punishment that animate Hillyard and Tombs' (2007) concern regarding criminalisation and punishment. On the other hand, we may note the equally obvious reference to the notion of proportionality of punishment, a cornerstone of modern day jurisprudence (Zedner 2004). The crux of the matter is that neither part of this dyad should be elevated or given precedence over the other. Indeed, based upon 
this revised reading and the clear conceptual linkages that emerge between notions of harm, loss and the punishment of transgression it seems illogical to force an artificial cleavage between crime and harm. In this context, not to mention the well-established centrality of harm to crime (Paoli and Greenfield 2013), Pemberton (2016) is perhaps inexpedient to separate 'social' and 'criminal' harms in such a way as to perpetuate false dichotomies. Certainly, what we end up with from this bid to carve out a zemiological niche that focusses solely upon the former at the expense of the latter is an unhelpful isolation of two interrelated concepts forcefully corralled into opposing scholarly camps.

Whilst what has been presented thus far is by no means a comprehensive history of zemia's genealogy, it nevertheless opens up a dialogue regarding its lexical scope and underutilised dialectical potential. It is perhaps worth noting that none of this is intended to diminish the contributions made thus far by zemiologists. Rather the intention is to expand, and where necessary reconceptualise, such work by drawing upon the full range of meaning contained within the word zemia. When reframed and viewed in this light, the organising theme around which the zemiological movement is built is heir to a broader theoretical and empirical focus than hitherto suspected. Evidently, the upshot is that the current drive to impose strict disciplinary borders between the study of crime and harm is misplaced since an accurate translation of zemia does not support the imposition of such boundaries. To proceed as if zemia simply represents 'the Greek word for harm' is not only conceptually inaccurate, but analytically, theoretically and empirically unproductive. Therefore, instead of divorcing the facet of harm from the broader contexts with which the word zemia is concerned, we must reconceptualise zemia's analytical reach in accordance with its full range of meaning. 


\section{Reconceptualising Boundaries}

In their drive to establish and develop zemiology as a new and comprehensive discipline distinct from criminology (Hillyard 2013; Pemberton 2016), many of the early zemiologists have been described as resembling quite closely positivist social scientists (Loader and Sparks 2011). This alleged resemblance can arguably be seen in a number of respects but perhaps most clearly in their attempt to secure "distinct borders and clear demarcations" between crime and harm and between criminology and zemiology (Young 2007, 9). It may also be seen in the use of official statistics to support the misnomer that "crime' consists of many petty events" and that such events would not "score particularly highly on a scale of personal hardship" (Hillyard and Tombs 2007, 11). Such an assertion arguably pays little regard to the experiential reality of crime or the very real consequences for those who experience this reality as harm in the empirical domain of everyday life. It serves no useful purpose to deny that "crime produces universally discernible and distressing harms to all sorts of victims" (Hall 2012, 160). Nor is it helpful to act as if crime and harm are essentially different currencies in some strange hierarchy of intellectual capital rather than representing two sides of the same coin.

However, this critique must be viewed in context. The principal driving force behind the emergence of the zemiological movement was a desire to "move beyond the narrow confines of criminology" (Hillyard et al. 2004b, 1). Admirably, the early contributors to this developing programme of study marshalled a movement to fight against the surging tide of a discipline that has historically favoured the investigation and analysis of 'conventional' volume crime. Certainly, it is no secret that politically influential strands of criminology continue to restrict themselves to this crime type and disregard crimes committed by or on behalf of the state, crimes that are technologically sophisticated and/or corporate in nature, and a plethora of un-criminalised harms that emanate from the way in which our current 
social system is organised. The effect is the obfuscation of the full extent of crime and harm present in today's world. The academic records show quite clearly that paradigmatically dominant strands of criminology have tended to treat crime, deviance and harm as separate yet occasionally overlapping concepts (Smith and Raymen 2016). Rather than view such phenomena through a suitably holistic analytical frame the dominant trend has been towards 'analytical individualism'. This is precisely what the early zemiologists were trying to rectify. Indeed, Hillyard et al. (2004b, 2) make it clear that "it is a central premise of this book that it makes no sense to separate out harms, which can be defined as criminal, from all other types of harm".

However, criminology and zemiology continue to be cast in opposing roles, as possessing some innate incompatibility that precludes any hope of collaborative integration. All too often during this casting process criminology is reduced to a "scarcely recognisable caricature" (Loader and Sparks 2011, 25). What emerges from this reduction is a conflation of diverse and multifaceted criminologies into a singular orthodox 'criminology' indubitably in service of the state and therefore controlled and constrained by governmental agendas and definitions (Hughes 2007, 2006). Whilst such an 'administrative' criminology undoubtedly does exist to some degree, it is not indicative of all criminology, or of criminology per se. Rather it is but one, albeit influential, form of criminology that emerged in the 1950s (Tierney 2010). Yet, rather than constituting a part of the sum total, this administrative form of criminology is often viewed as 'criminology ad totum'. This simplistic and convenient reading of what criminology is or is not allows the fabrication of a suitable 'straw(wo)man' that is easy to criticize and rally against (Hughes 2006, 2007).

Whilst the pluralistic nature of criminology has to some extent been acknowledged, there is still a tendency to view criminology as a discipline inextricably constrained by the remit of the state and the limits imposed by its drive for pragmatism (Hillyard and Tombs 
2017). This is probably true for the most part but not in its entirety. There are a number of important yet understated criminological developments that have undoubtedly taken harm seriously. For example, the increasingly popular ultra-realism utilises an advanced conception of harm to explore the reality of our times and explain why individuals inflict harm on others in pursuit of self-interest (Hall and Winlow 2015). In doing so, ultra-realism provides a genuine alternative to the dominant paradigms currently constraining the discipline. This new approach, which has made great strides towards ontologically grounding the concept of harm, represents a discernible break from state-centric approaches and does not attempt simply to extend conceptions of what constitutes 'crime'. In other words its object of study is not determined by the state. Indeed, ultra-realism has recently formed the basis of numerous stringent critiques of contemporary social issues perhaps thought to be outside the remit of 'traditional' criminological inquiry (Hayward and Smith 2017; Wakeman 2017). For instance, ultra-realism has provided the philosophical and theoretical foundations for the development of a 'deviant leisure' perspective which seeks to explore the harms associated with commodified forms of leisure (Hayward and Smith 2017).

It is salient to emphasise that criminology and zemiology are by no means unified entities. Indeed, both fields are characterised by significant paradigmatic junctures, widely varying views on the nature of 'their' subject matter and the relevancy and legitimacy of content, as well as a fair bit of infighting. Even the most cursory scan through the contents of the voluminous criminology textbooks now available will reveal a scattered history of a discipline very much 'divided amongst itself'. This is also true of zemiology, if perhaps much less evident, for it currently has been unable to pull together all the existing work into a unifying disciplinary perspective (Hillyard 2013). What appears evident throughout the emerging zemiological literature is the presence of long running tensions between those who wish to abandon and move entirely beyond criminology and those who wish to incorporate 
the analysis of social harm within the fold of critical criminology (Pemberton 2016). Whilst both criminology and zemiology can of course exist independently from each other, the fundamental upshot is that both criminology and zemiology have by and large failed to identify the numerous strands of connective tissue shared by these two social scientific bodies. Rather than celebrating meaningful and productive synergies both bodies are continuously misidentified and often reduced to a series of simplistic signifiers.

Hillyard (2013) has, for example, identified some of the abovementioned tendencies at play in 'criminology's' reaction to the emergence of zemiology. In an admittedly tonguein-cheek topology Hillyard identifies five types or forms of reaction that zemiology has received on behalf of 'criminology' which he refers to as colonialists, imperialists, nationalists, reluctant nationalists and misguided nationalists. None of these support an independent zemiology free from the clutches of a 'state-centric' 'criminology'. Quite simply, it appears that influential sections of criminology have not taken the zemiological movement seriously enough. Certainly, this is to some extent reflected in Newburn's (2017) enervations regarding the potential longevity of the movement. However, at the same time that we see criminology's cagy response to zemiology, we witness what might be termed the 'separatist' or 'independent' branch of zemiology offer its own caricatured interpretations of 'criminology'. Interpretations that, as already noted, see 'criminology' as being infinitely confined to an operative view defined by the state and its legal system from which it is seemingly unable to free itself. Yet this ostensibly fails to acknowledge that a great deal of the salient criticisms laid at criminology's door have been immanent. That is to say they have emerged from within the discipline of criminology itself, emanating largely from the work of various influential critical and radical criminologists who laid much of the groundwork upon which the Beyond Criminology project would later tread (Loader and Sparks 2011; Hughes 2006). 
In the years since the original publication of Beyond Criminology, the simple caricature of criminology noted above has persisted (Hillyard and Tombs 2007; Hillyard 2013; Pemberton 2016). Advances in the realms of critical and radical criminology and the multiplicity of perspectives that have facilitated the expansion of the discipline's intellectual scope (Ross and Richards 2003) have been largely ignored or downplayed. Moreover, there appears to be little acknowledgment that both criminology and zemiology are interdisciplinary rendezvous subjects capable of incorporating and utilising a broad gamut of perspectives to explore and explain pressing social phenomena. There also appears to be little recognition that some of the most significant contemporary advances in both of these disciplines have been made by those willing to expand rather than abandon the criminological imagination by incorporating sophisticated and cutting-edge approaches from cognate fields of study (Hall 2012; Hall and Winlow 2015; Yar 2012; Raymen 2016; Ellis 2016).

Even when some concessions are made regarding criminology's long history of incorporating social harm within its orbit of inquiry we are often met with yet more confusing distinctions and demarcations. For some, the study of social harm is now firmly and legitimately located within the purview of critical criminology and does not necessarily "capture the notion of a discipline" (Hillyard 2013, 232-233). Therefore reference to zemiology is stressed in order to distinguish the emerging new discipline from its criminological counterpart, and more importantly, to demarcate those who wish to 'move beyond' criminology from those who wish to broaden its parameters (Hillyard 2013; Pemberton 2016). For others, however, social harm is "the organising concept for zemiology as a field of study" (Pemberton 2016, 7). There undoubtedly remains some confusion here as to whether or not immutable conceptual differences separate 'zemiology' and the 'social harms' approach. Meanwhile, amidst all the confusion of hastily formed distinctions and demarcations, influential sections of criminology and zemiology continue to jostle for 
position. Particular schools of thought, which are inaccurately portrayed as being the quintessential face of their discipline par excellence, thus continue to over-determine and trivialise 'conventional' volume crime, and over-analyse and downplay the crimes of the poor and the harms committed by the state. However, amongst all the jostling these influential strands of criminology and zemiology have missed the point; they have failed to notice the pertinent crossovers that a more collegial approach might otherwise reveal.

Rather than acknowledge that there are numerous patches of common ground to be found between criminology and zemiology, we are instead left with overstated differences predicated upon an inaccurate understanding of what zemia means. Indeed, as has been shown, nowhere in zemia's genealogy is there to be found any innate, natural or inevitable fault lines. Instead, an accurate reading of the meaning of zemia reveals closer connections between harm, crime, and the punishment of legal transgression than a number of academics have previously suspected, or have been willing to admit. This is not to suggest that we should reposition the concept of 'crime' at the forefront of our analysis, or that criminal harms represent the most salient dangers facing the social world, or indeed that the answer lays in completely dispensing with 'crime' as an empirical and analytical object of inquiry (Yar 2012). It is simply to note that if we are to attain a more holistic understanding of both criminalised and un-criminalised harms and their multifaceted interconnections we must transcend the perpetuation of false dichotomies and artificial disciplinary boundaries. At the very least, it highlights that abstract references to partial notions of zemia cannot be used to support the imposition of false alternatives between crime and harm or between criminology and zemiology.

Instead of facilitating a more holistic exploration of criminalised and un-criminalised harms, the current dominant tendency to force an imaginary dualism between the study of crime and harm results in a failure to consider multiple layers of hidden victimage (Kotzé and 
Boukli 2016). Indeed, by disconnecting criminal and un-criminalised harm we risk doing precisely what Hillyard et al. (2004b) explicitly wished to avoid - capturing only isolated strata of contemporary victimisation's multifaceted complexity. This is precisely because 'crime' and 'harm' are interactive and integrative bilateral processes. One may either ignite or emanate from the other in ways that resemble a bilateral implosion or fusion, thereby creating specific yet nuanced and multifaceted phenomena that cannot be subjected to analytical dualism. The early zemiologists undoubtedly recognised and understood part of this complexity for they drew attention to the inadequacy of concentrating solely upon events officially defined as 'crime', which certainly excludes a great many un-criminalised harms (Hillyard and Tombs 2004). However, in a similar move for which they criticise 'mainstream' criminology, some have predominantly trained their analytical lens to focus upon un-criminalised harms to the near exclusion of its criminalised counterpart (Pemberton 2016). This somewhat unilateral focus, generally centred upon state crimes and systemically induced social harms, largely fails to acknowledge "the second layer of hidden victimage often perpetrated and experienced by the very victims of these state crimes and systemic harms" (Kotzé and Boukli 2016, 820).

In doing so some sections of zemiology display a tendency to downplay the complex relationship between crime and harm, often labelling the former as 'petty' (Hillyard and Tombs 2004, 2007; Pemberton 2016). However as criminology has so often reminded us, there is nothing 'trivial', 'petty' or insignificant about persistent offences or incivilities largely perpetrated by and against those in precarious socioeconomic positions (Young 1988, 1975). Indeed, the cumulative effect of such occurrences can have devastating consequences. The tragic case of Fiona Pilkington who, having endured years of abuse from local youths, killed herself and her daughter in October 2007 is a case in point. This, as Chakraborti (2010, 1) notes, undoubtedly "highlights in no uncertain terms the devastating cumulative impact of 
so-called 'low-level' incidents". Far from merely representing some unimportant mass of officially defined, discrete and measurable incidents fixed in space and time, 'crime' is fluid (Hall 2005). It ebbs and flows within the broad channels of wider socioeconomic and politico-cultural contexts as it interacts, causally and/or effectually, with serious social harms. Whichever way you cut it, criminalised and un-criminalised harms coexist in a complex relationship characterised by a finely nuanced interplay of harmful absences and events that damage not only individual human subjects but the wider social body.

We cannot therefore continue to arbitrarily separate crime and harm in such a way as to subject one side of the equation to critical analysis only at the expense of the other. To do so evidently results in a rather stilted and incomplete view of such complex social phenomena. Instead, these two facets must be viewed together through a holistic analytical framework developed through a thoroughly integrated approach towards the study of criminalised and un-criminalised harms. This prospect raises a number of pertinent questions as to precisely how we might achieve such a thoroughly integrated approach. Whilst this chapter can offer no definitive blueprint that neatly sketches out the way forward, it can nevertheless be suggested that the first step in this proposed direction must necessarily be to dispense with the unhelpful tendency to cast criminology and zemiology as diametrically opposed entities. Accordingly, when confronted with the increasingly popular question 'criminology or zemiology?' the reply should be an emphatic 'yes, please!', for this is arguably the only logical response.

\section{Towards an Integrated Approach}

What is being advocated here is a simple refusal of choice between false alternatives (Žižek 2000). There is no real alternative on offer here, for each 'option' simply represents one 
distorted lens from which to view and make sense of crime and harm. It is akin to being asked to choose between using only your left or right eye, leaving you straining desperately for a broader vision. To choose one over the other is therefore to risk a myopic and limited view of all that ails society, precisely because such ailments are often made up of complex and subtlety interconnected forms of various criminalised and un-criminalised harms. Indeed, the pervasiveness of systemic harms is unquestionable (Hillyard et al. 2004a; Davies, Francis, and Wyatt 2014), yet such harms, which are subject to intense zemiological, and sporadic critical criminological scrutiny, often precipitate criminal acts that are not always afforded the same attention. In part, this may be due to an entrenched fear that to draw attention to these precipitated criminal acts is to further criminalise the poor. Yet far from protecting the powerless, this equation of analysis with criminalisation serves only to mask the true extent of their plight (Young 1988; Currie 2009; Hall and Winlow 2015). Indeed, not only are the poor subject to numerous social, political and economic injustices, but for many the path taken to ameliorate such inequitable social circumstances engenders further harm and misery. For instance, many of those who constitute the indivisible remainder of neoliberalism's wasteful and rejecting logic (Bauman 2000) often have little option than to offset their socioeconomic redundancy by becoming involved in various aspects of the hidden economy (Lea 1999, 2002). Far from constituting 'petty' acts of crime, such involvement is fraught with harm for all those involved. Individuals are forced to flirt dangerously with illegality and risk being absorbed into more dangerous criminal enterprises that carry heavy penalties as they try to negotiate the boundaries between harmful and beneficial criminal activity (Lea 1999, 2002). This should serve as a crucial reminder that the roles of victim and offender are not mutually exclusive but often overlap extensively. Nowhere is this made clearer than in the literature documenting the victimisation of the homeless. This body of literature clearly demonstrates how such individuals suffer "the ultimate state of 
victimisation" since they are victimised not only by the state and the general public, but indeed from within the homeless population itself (Fitzpatrick, La Gory, and Ritchey 1993, 366; Garland, Richards, and Cooney 2010; Lee and Schreck 2005).

Rather than being viewed as unimportant 'petty' crime undeserving of our attention, such examples should be understood as a corollary of broader systemic harms wrought by neoliberal market capitalism. Accordingly, it makes little sense to view 'crime' as somehow independent of harmful absences or processes that result from the way in which we organise our social system. Instead, it must be acknowledged that 'crime' and 'harm' are two sides of the same coin. Crucially, there are fundamental synergies between criminology and zemiology that, if brought to bear on contemporary academic thought, could facilitate the exploration of a broader range of societal ills than each is capable of achieving alone. Perhaps now more than ever it is necessary for us to explore with more rigour the interconnected complexities of crime and harm by connecting the dots rather than forcing a wedge between criminology and zemiology. If this is to be achieved, we must dispense with unhelpful dichotomies that incorrectly advance criminology and zemiology as inherently polarised and competing projects based upon a limited understanding of zemia. Not only does such a view show little comprehension of zemia's genealogy, but it encourages both analytical and empirical inertia. As we begin to see ever growing tensions coupled with increasing levels of visible social dislocation manifest at alarming rates (Žižek 2012), we can afford no disciplinary myopia but require all of our intellectual acuity. Indeed, as Thomas Hardy once noted, "if a way to the better there be, it lies in taking a full look at the worst" (cited in Becker 1975, xi, emphasis added).

This is precisely the point and it bears labouring; a full look at the worst necessitates an integrated approach capable of exploring and explaining both criminalised and uncriminalised harms. It requires a concerted effort to traverse artificial disciplinary borders and 
dispel fierce ‘topical guardianship'. Instead of ignoring phenomena because they are deemed to be outside of some supposedly predefined remit, or trivialising acts of illegality because they are not deemed 'serious enough', we should have greater cognisance of their complex, multifaceted and nuanced interconnections. Yet despite the desperate need of such an integrated approach, criminology and zemiology continue to be cast as incompatible entities characterised by what are thought to be immutable differences that presuppose a necessary separateness. Undoubtedly, as Hillyard and Tombs (2017) have recently noted, a great deal more needs to be done in order to explore and establish the relationship between criminology and zemiology. This could perhaps be taken a step further by suggesting that during this process more needs to be done to affirm their compatibility and reciprocity.

\section{Conclusion}

Since the emergence of zemiology as a new discipline seemingly distinct from criminology (Hillyard 2013), many of those within its fold have operated under the assumption that zemia, the organising concept around which zemiology is built, simply represents 'the Greek word for harm'. This lingering oversimplification has had profound and lasting effects, not least of all because it has all too often been used as a conceptual hammer to drive an artificial wedge between the study of crime and harm. Having laid the groundwork in the foregoing discussions, it is appropriate to answer the two questions posed in the introduction to this chapter. The answer to both questions is of course a firm 'no'. The meaning of zemia has not been adequately explored or applied; nor does a holistic reading of the meaning of zemia substantiate the tendency to position crime and harm and criminology and zemiology as diametric opposites.

It is clear that there has hitherto been insufficient attention paid to the highly nuanced lexical formation of zemia. Instead, the word has been carved up and trimmed of its 
numerous other connotations so that it commonly conveys only a portion of its broader meaning. Accordingly, this chapter has sought to trace with more accuracy the semantical complexities of zemia and in doing so has demonstrated that it possess a broader range of meaning than previously acknowledged. Far from simply denoting harm, zemia has a clear association with crime and its punishment. In fact, an accurate reading of zemia clearly shows that it denotes closer connections between harm, crime and its punishment than many academics would perhaps care to admit. Nowhere in zemia's genealogy is there to be found any support for the imposition of artificial boundaries or false dichotomies between crime and harm or between criminology and zemiology. In reality, quite the opposite is true. That is to say that a more thorough examination and application of the word zemia actually implies and facilitates a more integrated approach between criminology and zemiology.

The importance of developing such an integrated approach should not be underestimated for criminalised and un-criminalised harms coexist in a complex relationship and as such cannot be sufficiently explored as isolated phenomena. Indeed, the multifaceted interplay of harmful absences and events or processes that surround both crime and harm cannot be arbitrarily divided and placed into neatly formed categories that 'belong' to certain disciplines. If we are to attain a more holistic understanding of both criminalised and uncriminalised harms, and their highly nuanced and complex interconnections, we must transcend artificially imposed disciplinary boundaries and the perpetuation of false alternatives between criminology and zemiology. Perhaps a good place to start is to acknowledge the speciousness of removing from zemia its clear association with crime and its punishment and forcibly limiting its denotation to various forms of un-criminalised harms. From here we may begin to analytically reconnect crime and harm and recognise the collaborative potential of criminology and zemiology to provide a stronger lens through which we may take a full look at the worst. 


\section{References}

Allen, Danielle S. 2000. The World of Prometheus: The Politics of Punishing in Democratic Athens. Princeton: Princeton University Press.

Balot, Ryan K. 2001. Greed and Injustice in Classical Athens. Princeton: Princeton University Press.

Bauman, Zygmunt. 2000. 'Social Issues of Law and Order'. British Journal of Criminology 40:205-221.

—. 2004. Wasted Lives: Modernity and its Outcasts. Cambridge: Polity Press.

Becker, Ernest. 1975. Escape from Evil. New York: The Free Press.

Boukli, Avi. 2019. Zemiology and Human Trafficking. London: Routledge.

Cairns, Douglas L. 2015. 'Revenge, Punishment, and Justice in Athenian Homicide Law'. Journal of Value Inquiry 49:645-665.

Chakraborti, Neil. 2010. 'Future Developments for Hate Crime Thinking: Who, What and Why?' In Hate Crime: Concepts, Policy, Future Directions, edited by Neil Chakraborti, 1-15. Cullompton: Willan Publishing.

Currie, Elliott. 2009. The Roots of Danger: Violent Crime in Global Perspective. New Jersey: Prentice Hall.

Davies, Pamela., Peter Francis, and Tanya Wyatt. Eds. 2014. Invisible Crimes and Social Harms. Basingstoke: Palgrave Macmillan. 
Ellis, Anthony. 2016. Men, Masculinities and Violence: An Ethnographic Study. London: Routledge.

Fitzpatrick, Kevin M., Mark E. La Gory, and Ferris J. Ritchey. 1993. 'Criminal Victimization among the Homeless'. Justice Quarterly 10:353-368.

Garland, Tammy S., Tara Richards, and Mikaela Cooney. 2010. 'Victims Hidden in Plain Sight: The Reality of Victimization among the Homeless'. Criminal Justice Studies 23:285301.

Hall, Nathan. 2005. Hate Crime. Cullompton: Willan Publishing.

Hall, Steve. 2012. Theorizing Crime and Deviance: A New Perspective. London: Sage Publications Ltd.

Hall, Steve., and Simon Winlow. 2015. Revitalizing Criminological Theory: Towards a New Ultra-Realism. London: Routledge.

Hayward, Keith., and Oliver Smith. 2017. 'Crime and Consumer Culture'. In The Oxford Handbook of Criminology, $6^{\text {th }}$ Edition, edited by Alison Liebling, Shadd Maruna, and Lesley McAra, 306-328. Oxford: Oxford University Press.

Henry, Stuart., and Mark M. Lanier. 1998. 'The Prism of Crime: Arguments for an Integrated Definition of Crime'. Justice Quarterly 15:609-627.

Henry, Stuart., and Dragan Milovanovic. 1996. Constitutive Criminology: Beyond Postmodernism. London: Sage Publications Ltd.

Hillyard, Paddy. 2013. 'Zemiology Revisited: Fifteen Years On'. In Critique and Dissent: An 
Anthology to Mark 40 Years of the European Group for the Study of Deviance and Social Control, edited by Joanna Gilmore, J. M. Moore, and David Scott, 219-233. Ottawa: Red Quill Books Ltd.

Hillyard, Paddy., Christina Pantazis, Steve Tombs, and Dave Gordon. Eds. 2004a. Beyond Criminology: Taking Harm Seriously. London: Pluto Press.

Hillyard, Paddy., Christina Pantazis, Steve Tombs, and Dave Gordon. 2004b. 'Introduction’. In Beyond Criminology: Taking Harm Seriously, edited by Paddy Hillyard, Christina Pantazis, Steve Tombs, and Dave Gordon, 1-9. London: Pluto Press.

Hillyard, Paddy., and Steve Tombs. 2004. 'Beyond Criminology?' In Beyond Criminology: Taking Harm Seriously, edited by Paddy Hillyard, Christina Pantazis, Steve Tombs, and Dave Gordon, 10-29. London: Pluto Press.

_. 2007. 'From 'Crime' to Social Harm?' Crime, Law and Social Change 48:9-25.

- 2017. 'Social Harm and Zemiology'. In The Oxford Handbook of Criminology, $6^{\text {th }}$ Edition, edited by Alison Liebling, Shadd Maruna, and Lesley McAra, 284-305. Oxford: Oxford University Press.

Hopkins Burke, Roger. 2014. An Introduction to Criminological Theory, 4th Edition. London: Routledge.

Hughes, Gordon. 2006. 'Review of Paddy Hillyard, Christine Pantazis, Steve Tombs and David Gordon (eds) Beyond Criminology: Taking Harm Seriously'. Social and Legal Studies 15:157-159.

- 2007. The Politics of Crime and Community. Basingstoke: Palgrave Macmillan. 
Kotzé, Justin., and Avi Boukli. 2016. 'Review of Invisible Crimes and Social Harms by Pamela Davies, Peter Francis and Tanya Wyatt'. British Journal of Criminology 56:818-820.

Lea, John. 1999. 'Social Crime Revisited'. Theoretical Criminology 3:307-325.

. 2002. Crime and Modernity: Continuities in Left Realist Criminology. London: Sage Publications Ltd.

Lee, Barrett A., and Christopher J. Schreck. 2005. 'Danger on the Streets: Marginality and Victimization among Homeless People'. American Behavioral Scientist 48:1055-1081.

Loader, Ian., and Richard Sparks. 2011. Public Criminology? London: Routledge.

Milovanovic, Dragan., and Stuart Henry. 2001. 'Constitutive Definition of Crime: Power as Harm'. In What is Crime? Controversies over the Nature of Crime and What to do About It, edited by Stuart Henry, and Mark M. Lanier, 165-178. Lanham: Rowman and Littlefield Publishers, Inc.

Muncie, John. 2000. ‘Decriminalizing Criminology'. In Rethinking Social Policy, edited by Gail Lewis, Sharon Gewirtz, and John Clarke, 217-228. London: Sage Publications Ltd.

—. 2013. 'Social Harm'. In The Sage Dictionary of Criminology, 3rd Edition, edited by Eugene McLaughlin, and John Muncie, 430-432. London: Sage Publications Ltd.

Muncie, John., Deborah Talbot, and Reece Walters. 2010. 'Interrogating Crime'. In Crime: Local and Global, edited by John Muncie, Deborah Talbot, and Reece Walters, 1-36.

Cullompton: Willan Publishing.

Newburn, Tim. 2017. Criminology, $3^{\text {rd }}$ Edition. London: Routledge. 
O’Connor, David K. 1991. 'The Aetiology of Justice'. In Essays on the Foundations of Aristotelian Political Science, edited by Carnes Lord, and David K. O’Connor, 136-164. Berkeley: University of California Press.

Paoli, Letizia., and Victoria A. Greenfield. 2013. 'Harm: A Neglected Concept in Criminology, a Necessary Benchmark for Crime-Control Policy'. European Journal of Crime, Criminal Law and Criminal Justice 21:359-377.

Pemberton, Simon. 2016. Harmful Societies: Understanding Social Harm. Bristol: Policy Press.

Raymen, Thomas. 2016. 'Designing-in Crime by Designing-out the Social? Situational Crime Prevention and the Intensification of Harmful Subjectivities'. British Journal of Criminology $56: 497-514$.

Ross, Jeffrey I., and Stephen C. Richards. 2003. 'Introduction: What is the New School of Convict Criminology?' In Convict Criminology, edited by Jeffrey I. Ross, and Stephen C. Richards, 1-14. Belmont: Wadsworth.

Saunders, Trevor J. 1991. Plato's Penal Code: Tradition, Controversy, and Reform in Greek Penology. Oxford: Oxford University Press.

Schwendinger, Herman., and Julia Schwendinger. 1975. 'Defenders of Order or Guardians of Human Rights?' In Critical Criminology, edited by Ian Taylor, Paul Walton, and Jock Young, 113-146. London: Routledge and Kegan Paul.

Smith, Oliver., and Thomas Raymen. 2016. 'Deviant Leisure: A Criminological Perspective'. Theoretical Criminology DOI: https://doi.org/10.1177/1362480616660188 
Sutherland, Edwin H. 1945. 'Is “White-Collar Crime” Crime?' American Sociological Review 10:132-139.

Tierney, John. 2010. Criminology: Theory and Context, 3rd Edition. Harlow: Pearson Education Limited.

Tifft, Larry L., and Dennis C. Sullivan. 2001. 'A Needs-Based, Social Harms Definition of Crime'. In What is Crime? Controversies over the Nature of Crime and What to do About It, edited by Stuart Henry, and Mark M. Lanier, 179-203. Lanham: Rowman and Littlefield Publishers, Inc.

Versnel, Henk S. 1992. 'The Festival for Bona Dea and the Thesmophoria'. Greece \& Rome $39: 31-55$.

Wakeman, Stephen. 2017. 'The 'one who knocks' and the 'one who waits': Gendered violence in Breaking Bad'. Crime, Media, Culture DOI:

https://doi.org/10.1177/1741659016684897

Yar, Majid. 2012. 'Critical Criminology, Critical Theory and Social Harm'. In New

Directions in Criminological Theory, edited by Steve Hall, and Simon Winlow, 52-65. London: Routledge.

Young, Jock. 1975. 'Working-Class Criminology'. In Critical Criminology, edited by Ian Taylor, Paul Walton, and Jock Young, 63-94. London: Routledge and Kegan Paul.

. 1988. 'Risk of Crime and Fear of Crime: A Realist Critique of Survey-Based Assumptions'. In Victims of Crime: A New Deal? Edited by Mike Maguire, and John Pointing, 164-176. Milton Keynes: Open University Press.

_ 2007. The Vertigo of Late Modernity. London: Sage Publications Ltd. 
Zedner, Lucia. 2004. Criminal Justice. Oxford: Oxford University Press.

Žižek, Slavoj. 2000. 'Class Struggle or Postmodernism? Yes, please!' In Contingency, Hegemony, Universality: Contemporary Dialogues on the Left, by Judith Butler, Ernesto Laclau, and Slavoj Žižek, 90-135. London: Verso.

2012. The Year of Dreaming Dangerously. London: Verso. 